\title{
The competition diallel and the exploitation and interference components of larval competition in Drosophila melanogaster
}

\author{
J. R. DE MIRANDA, ${ }^{*}$ M. HEMMAT† \& PAUL EGGLESTON \\ Department of Genetics and Microbiology, University of Liverpool, Liverpool L69 3BX, UK
}

\begin{abstract}
A logistic model of the competition diallel is presented based on two linear parameters for the exploitation component of competition, namely the acquisition rate $(f)$ and utilization efficiency $\langle u\rangle$, and one linear parameter for the interference component of competition $(i)$. This interference component encompasses all phenomena that are uniquely related to duocultures, such as resource partitioning, mutual stimulation, inhibition and complementation. The model uses yield-density regression coefficients ( $c$-values), but could be adapted to suit other variates that account for both competitor density and relative frequency. In Drosophila larval competition most interference is negative and depresses the performance of duocultures with respect to monocultures, over and above that expected from shared exploitation of a common resource. Even in the closely controlled competitive conditions of these experiments this interference accounts for a considerable proportion of the total variation. The isolation of a general, and therefore predictable, interference component may prove useful in agriculture when assessing the relative importance of mixture effects to the yield potential of different crops.
\end{abstract}

Keywords: competition, diallel, exploitation, interference, yield-density regression.

\section{Introduction}

The main benefit of mixing different crops or cultivars is that the combined yield of such mixtures often exceeds the yield of either crop grown as a pure stand. Temporal and spatial variations in the nutritional requirements of the crops means that the total resource available is greater for the mixture than for either monoculture and more efficient use is made of the land (Chowdury \& Hodgson, 1982; Spitters, 1983b). Such benefits are best estimated by the Relative Yield Total (de Wit \& van den Bergh, 1965) or Land Equivalent Ratio (Willey \& Osiru, 1972) and with the advent of yield-density regression analyses for mixtures (Mather \& Caligari, 1981; Wright, 1981; Spitters, 1983a) the RYT or LER can be optimized by scanning through the absolute and relative densities of the two crops (Spitters, 1983b). Benefits purely due to mixing are therefore dependent on the difference between the requirements of the crops. This makes it difficult to

*Present address: John Innes Institute, Colney Lane, Norwich NR4 7UH, UK.

†Present address: Shahrekord Agricultural College, PO Box 115, Shahrekord, Iran. predict the results of mixing a priori. Much progress has been made with physiological plant growth models (Spitters \& Aerts, 1983; Spitters, 1986; Johnson et al., 1989; Lim et al., 1990) where the combined growth of different crops is simulated, but it remains difficult to determine whether the plants are drawing from the same or different resources. Furthermore, not all mixture effects are necessarily beneficial (van den Bergh, 1968; Spitters, 1979). Changes in soil micro-flora and fauna, shading effects, the release of plant secondary metabolites, plant disease and pathogen or vector interactions could all have either antagonistic or synergistic effects, if not on the total biomass then possibly on the harvested component of a crop. Any general, and therefore predictable, benefit associated with mixing may also be obtained from analysing many interrelated mixtures. Such competition diallels have long been popular in competition studies. The diallel is formed by competing each strain with every other strain, including itself, and recording the performance of the primary (indicator) genotype in the presence of various associate competitors. However, with notable exceptions (McGilchrist \& Trenbath, 1971) the analysis of such diallels has been largely empirical 
(Williams, 1962; McGilchrist, 1965; Norrington-Davies, 1967, 1968; Breese \& Hill, 1973; Mather \& Caligari, 1983; Eggleston, 1985; de Miranda \& Eggleston, 1987, 1988c, 1989) with little regard for the biological determinants underlying the diallel. Hence, in this paper we present an analytical model for the competition diallel based on three linear biological parameters, representing both the exploitation (acquisition and utilization of a common resource) and interference (unique resources and mixture benefits) components of competition (Birch, 1957). It integrates aspects of most of the analyses mentioned above and incorporates absolute and relative density effects through the use of yield-density regression slopes, or $c$-values, as entries for the diallel, rather than the more traditional total yields of 50/50 mixtures. The arguments are based on the interactions which occur between larvae of Drosophila melanogaster when competing for a fixed amount of food, using percentage survival as a measure of competitive success. However, the principles and conclusions apply equally to other measures of competitive success, such as body weight or plant yield, and to situations where the limitation concerns the rate of nutrient supply, rather than the total amount.

\section{Materials and methods}

Competition took place in glass vials containing $5 \mathrm{ml} 2$ per cent bacto-agar and $55 \mathrm{mg}$ yeast (YSC-2, Sigma) dispensed as a solution. The vials were seeded with even-aged eggs of the various genotypes, using $(30,0)$, $(60,0),(90,0)$ and $(120,0)$ eggs per vial for the monoculture density series and $(30,90),(60,60)$ and $(90,30)$ eggs of either genotype for the duoculture density series. Seven phenotypically distinct inbred lines of Drosophila melanogaster were used, namely a selected slow feeding wild type strain (Burnet et al., 1977), the inbred lines Texas T25 and T16 (Linney et al., 1971) marked with $y^{2}$ and $w^{\mathrm{a}}$ respectively (Mather \& Caligari, 1983) and the mutant stocks $p n, w, v$ and $e$, details of which can be found in Lindsley \& Grell (1967). For each of these a monoculture density series and all possible combinations of duoculture density series were raised. The whole experiment was replicated four times, individually randomized and incubated at $25^{\circ} \mathrm{C}$. Upon emergence of the first adults, flies were collected daily for 10 days, grouped according to phenotype and weighed en masse. The proportion of eggs surviving to adulthood $(p)$ at each density was transformed to angles $\left(p_{\mathrm{a}}\right)$ and was analysed using the linear regression procedure of Mather \& Caligari (1981). The mean adult weight $(\bar{w})$ was analysed using a hyperbolic regression (Snedecor \& Cochran, 1980; Spitters et al., 1989). This is similar to using $1 / \bar{w}$ in a linear regression procedure, but yields superior estimates of the regression coefficients and circumvents the error variance heterogeneities introduced by transforming $w$ to $1 / \bar{w}$ (Spitters et al., 1989). The fit of the data to the regression models was tested by comparing the residual regression variance with the replicate error variance and was found to be acceptable in all cases. The replicate error variance was used to calculate the error variances associated with the regression parameters, as it was generally larger than the residual regression variance. None of the genotypes displayed non-competitive larval mortality (de Miranda \& Eggleston, 1988b).

\section{Analysis of the diallel}

The simplest form of competition occurs in monoculture (Fig. 1). All competitors have the same characteristic feeding rate, such that the proportion of larvae surviving at each density is dependent only on the efficiency with which the food is used to produce adult flies. A high efficiency will result in better survival at the higher densities, creating a shallow slope and therefore a low $c$-value. The monoculture $c$-value is therefore related to the efficiency $(u)$ of each genotype.

$$
c_{x x}=1 / u_{x} .
$$

The pattern of survival in duoculture is complicated by the different feeding rates of the two genotypes. If the feeding rates of the genotypes are identical then the allocation of food would be the same for all individuals, regardless of genotype, and survival of each genotype would again depend only on its utilization efficiency. The $c$-value of each genotype in duoculture would therefore be identical to its monoculture $c$-value (Mather \& Caligari, 1981). However, a higher feeding rate for genotype $x$ ensures that it acquires extra food at the expense of genotype $y$. Consequently, genotype $x$ will survive better at each density in duoculture than in monoculture, and increasingly so when there are more $y$ s than $x$ s to compete with. This will all be reflected by a lower $c$-value. As the food gained by genotype $x$ is at the same time lost by genotype $y$, gain and loss must be equal in magnitude, and is related directly to the difference in the feeding rates of genotypes $x$ and $y$. Therefore,

$c_{x x}=1 / u_{x}$

$c_{x y}=1 / u_{x}\left[1-\left(f_{x}-f_{y}\right)\right]$,

where $f$ represents the feeding rate and $u$ the utilization efficiency. The feeding rate differences are subtracted from 1 , rather than added to 1 since in yield-density 
Fig. 1 Schematic representation of the yield-density regression analysis of Mather \& Caligari (1981) for a substitution design showing the (indicator, associate) competitor densities. $b_{\mathrm{m}}, b_{\mathrm{d}}$ and $e$ refer to the monoculture and duoculture regression slopes and the reference density value respectively. $c_{\mathrm{mm}}$ and $c_{\mathrm{md}}$ refer to the corresponding mono- and duoculture $c$-values.

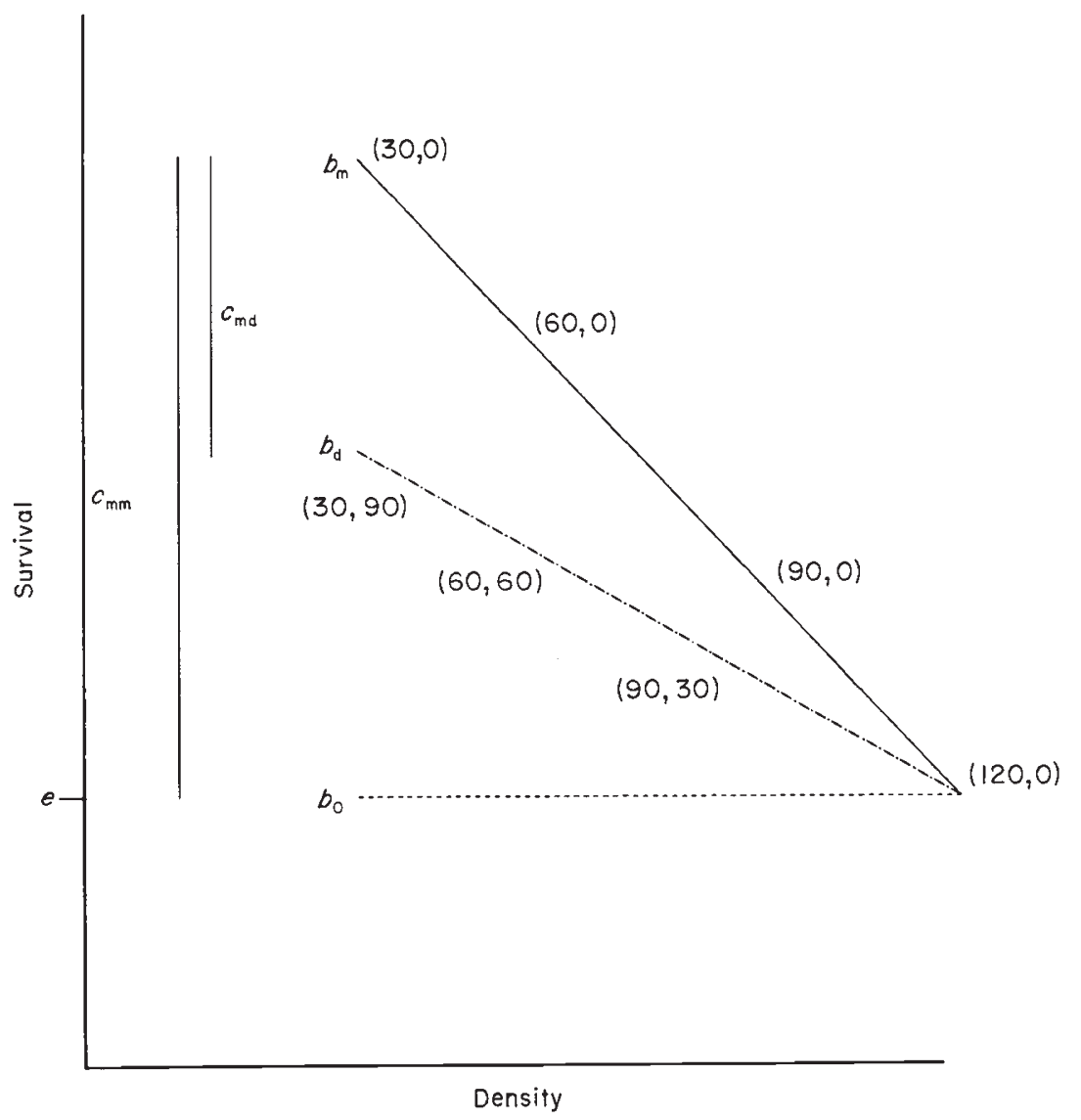

regression analyses, competitive strength is represented by a low $c$-value. These equations explain many properties of the competition diallel. If the feeding rates are identical then the duoculture and monoculture $c$-values of each genotype will be the same, as explained before. The feeding rate differences will tend to produce a negative correlation between the row and column means, but variation for the utilization efficiency $(u)$ will disrupt this correlation. Dividing all indicator $c$-values by their corresponding monoculture $c$-value removes the variation due to the differences in $u$ (and any effects of a correlation between utilization efficiency and feeding rate, de Miranda \& Eggleston, 1988a) and should improve the negative correlation between sensitivity (rows) and pressure (columns) caused by the feeding rate differences. The most important feature of such a corrected diallel is that the duoculture gains and losses should cancel, i.e. their average should equal 1.0. This would imply that the total exploitation potential of the resource by both genotypes is the same in monoculture as it is in duoculture and that the final yield of the duoculture mixture is dependent solely on how the resource is shared and what use each genotype can make of its share. This concept is similar to the Relative Yield
Total and the Land Equivalent Ratio. Any duoculture average which differs from 1.0 implies the presence of positive or negative interference. As competitive strength is rewarded with a low $c$-value, an average value $<1.0$ indicates positive interference, where mixing gives an extra advantage to one or both genotypes over and above that expected from shared exploitation of a common resource, while a value $>1.0$ implies negative interference where the genotypes are (mutually) antagonistic. In larval competition, waste products may spoil fresh food or provide an exclusive new resource, media conditioning can involve the release of secondary metabolites either harmful or beneficial to the other genotype (Sang, 1949; Dawood \& Strickberger, 1964; Weisbrot, 1966; Budnik \& Brncic, 1975) and burrowing can either hinder or help the other genotype depending on its preferred mode of foraging (Godoy-Herrera, 1977; Sokolowski, 1982). In plant competition it is through such interference, or ecological combining ability (Harper, 1967; Hill, 1990) that mixtures can perform better than both monocultures. For example, rooting length differences between the indicator plant and various associate plants make a larger total resource available from which both indicator and associate can benefit (Baan- 
Hofman \& Ennik, 1982). This benefit effects all duoculture combinations in a general manner, linked to the indicator genotype, while slight variations between different associates in the amount of new resource made available (variations in rooting length differences with the indicator genotype) provide the specific interference component. This is illustrated in Fig. 2, which concerns the duocultures between indicator plant $\mathrm{A}$ and associates $\mathrm{B}, \mathrm{C}$ and $\mathrm{D}$. Genotype $\mathrm{A}$ roots much deeper than $\mathrm{B}, \mathrm{C}$ or $\mathrm{D}$. This makes a unique resource available for $\mathrm{A}$ in all duocultures (represented by $i_{\mathrm{A}}$ ) enhancing its own performance as indicator. Genotypes B, C and D also benefit from the rooting habit of genotype $\mathrm{A}$ and this will contribute to $i_{\mathrm{B}}, i_{\mathrm{C}}$ or $i_{\mathrm{D}}$ when $\mathrm{B}, \mathrm{C}$ or $\mathrm{D}$ are analysed as indicator competitors. The remaining resource, represented by the shaded area, is shared between the competitors and its allocation is therefore determined by the acquisition rate differences between the genotypes. These effects are added to the model as follows

$c_{x x}=1 / u_{x}$,

$c_{x y}=1 / u_{x}\left[1-\left(f_{x}-f_{y}\right)-i_{x}\right]$,

where $i$, representing general interference, is subtracted rather than added, such that any beneficial interference which would lower the $c$-value is repre- sented by a positive value. Furthermore, $i$ is included inside the brackets, because the final expression of any advantage gained through interference is still subject to the utilization efficiency $(u)$. The simplest way to resolve these parameters is to use the monoculture $c$ values to estimate $u$ and to use the corrected diallel to separate the $f$ and $i$ components, with any residual variation in the corrected diallel forming the specific interference component. The corrected diallel yields a set of simultaneous equations containing all $f$ and $i$ effects which, for any diallel larger than $2 \times 2$, produces several solutions for each $i_{x}$. These can be combined into a single estimate of $i_{x}$ using least squares. However, it is not possible to obtain absolute values for $f_{x}$ because only the differences between the feeding rates (and not the values themselves) are orthogonal. Hence the estimates for $i$ are added to or subtracted from the relevant entries in the corrected diallel, leaving only the $f$ components and the residual variation. Relative estimates for the feeding rates can be obtained subsequently by setting each $f_{x}$ to 1 in turn and then calculating the values for the remaining $f_{x}$ s. This yields several estimates for each $f_{x}$, the average of which can be taken as its true relative value. It can also be shown that including $i$ as a column effect $\left[c_{x y}^{\prime}=1-\left(f_{x}-f_{y}\right)-i_{y}\right]$ gives the same solutions to the simultaneous equations as including $i$ as a row effect $\left[c_{x y}^{\prime}=1-\left(f_{x}-f_{y}\right)-i_{x}\right]$. This

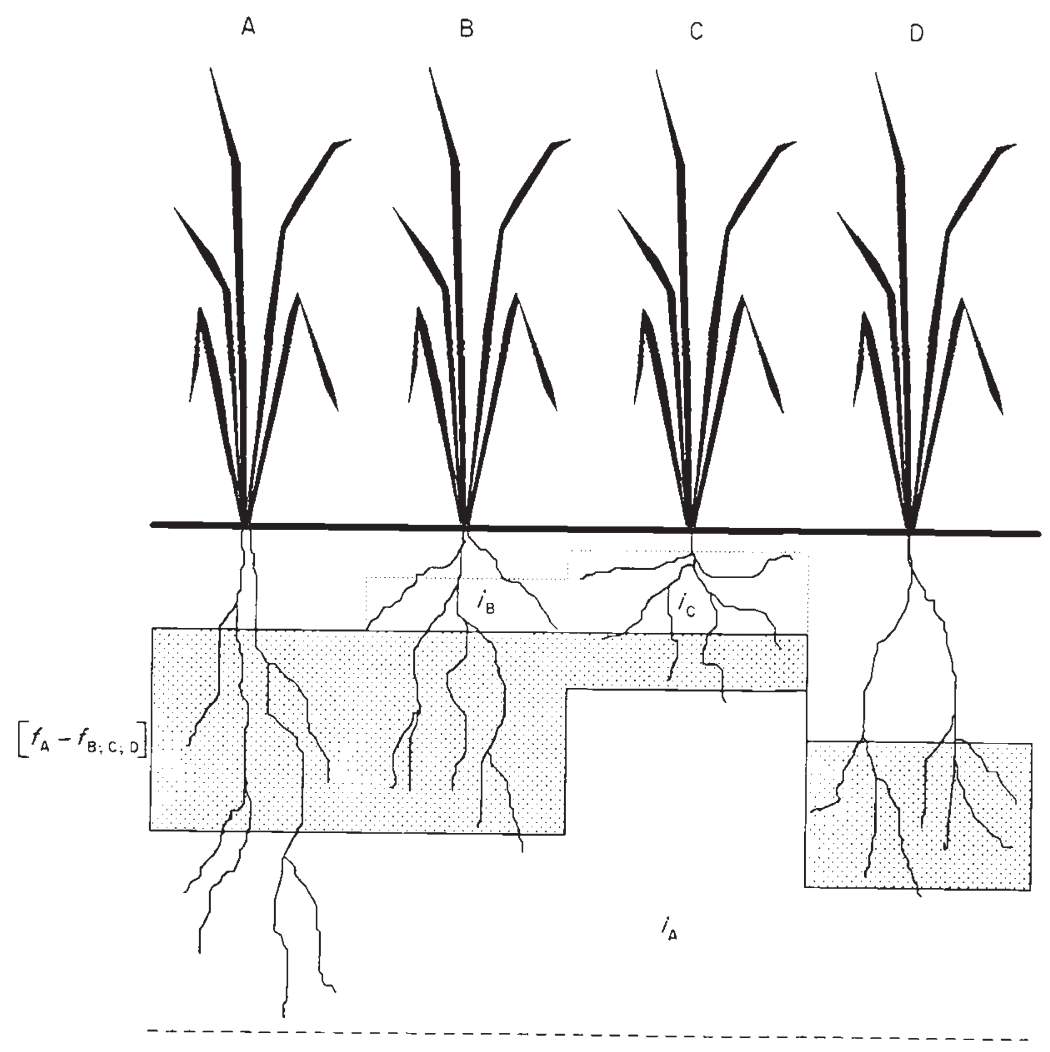

Fig. 2 Diagramatic representation of the various components of the competition diallel model using rooting length differences as the basis for resource partitioning. Plant $A$ is the indicator competitor, plants B, C or D the associate competitors. The shaded area refers to the exploitation component of competition, where both indicator and associate plants draw from the same resource which is unequally distributed to the plants according to their ability to acquire the resource [represented by $\left.\left(f_{\mathrm{A}}-f_{\mathrm{B} ; \mathrm{C} ; \mathrm{D}}\right)\right]$. $i_{\mathrm{A}}$ refers to the advantage gained by the indicator genotype by drawing from a unique resource when in association with competitors $\mathrm{B}, \mathrm{C}$ and D. $i_{\mathrm{B}}$ and $i_{\mathrm{C}}$ similarity refer to the unique resource advantage for genotypes $B$ and $C$ when in duoculture with genotype $\mathrm{A}$, which will contribute to the average estimates of $i_{\mathrm{B}}$ or $i_{\mathrm{C}}$. Genotype $\mathrm{D}$ obtains all its resources through the exploitation component of competition, when in duoculture with genotype $\mathrm{A}$. 
is less of a paradox than it appears. For example, with reference to Fig. 2 it could also be argued that indicator genotype A only gains an extra resource because of the shorter rooting habits of $\mathrm{B}, \mathrm{C}$ and $\mathrm{D}$, and that any advantage gained by $\mathrm{A}$ is therefore a property of the associate genotypes, in the form of $i_{\mathrm{B}}, i_{\mathrm{C}}$ and $i_{\mathrm{D}}$. Similarly, with any other perceived advantage it can equally be argued that it is either 'taken' by the indicator genotype ( $i$ as a row effect) or 'given' by the associate genotype ( $i$ as a column effect). However, while there is no distinction between these two versions of the model with respect to the estimation of $i$, it does affect the estimation of the relative feeding rates. It can be shown, with simulated corrected diallels, that subtracting $i_{x}$ from rows produces different estimates of the feeding rate differences $\left(f_{x}-f_{y}\right)$ than subtracting $i_{x}$ from columns, even though in both cases the feeding rate differences are orthogonal across the leading diagonal. It is possible, in practice, to decide whether the data is best analysed with $i$ as a row effect or as a column effect. From equation (2) it is apparent that without $i$ there should be equal variation between the row means and column means of the corrected competition diallel. The same is true for any $2 \times 2$ corrected diallel that includes $i$ as a row effect, but in larger diallels the $i$ components make increasingly cumulative contributions to the row totals, whereas the contributions to the column totals tend, increasingly, towards the average. This means that with increasing diallel size the variation between rows (sensitivity) becomes progressively larger compared to the variation between columns (pressure). The difference between the row and column sums of squares for a corrected diallel with $i$ as a row effect, is

$$
\begin{aligned}
& {[(n-2) / n] *\left[(n-1) \sum_{x=1}^{n} i_{x}^{2}-2 \sum_{x=1}^{n} \sum_{y=1}^{n}\left(f_{x}-f_{y}\right) i_{x}\right.} \\
& \left.-2 \sum_{x=1}^{n} \sum_{y=1}^{n} i_{x} i_{y}\right]
\end{aligned}
$$

where $n$ is the size of the diallel and $i$ and $f$ are as defined previously. This expression is dominated by the first term. The second term is simply the summed cross products of the feeding rate difference and $i_{x}$ in each cell, which are positive above the leading diagonal and negative below it. They will largely cancel each other, depending on the size and sign of $i_{x}$ s. The third item is also small compared to the first, especially if the $i_{x}$ s differ in sign. Note that if $n=2$ (a $2 \times 2$ diallel) no difference exists between the row and column sums of squares, which explains why the analysis of RYTs or corrected $c$-values only becomes meaningful in diallels larger than $2 \times 2$. The implication of equation (4) is that if there is more variation between rows than between columns, then the model with $i$ as a row effect is generally more suitable. If the converse is true then the model with $i$ as a column effect is preferable. Both the feeding rates and general interference are dimensionless parameters; the feeding rates because they are relative estimates and interference because it is largely an extension of the utilization efficiency. The dimensions for the utilization efficiency are $\Delta$ weight $/ \Delta$ area for the mean adult weight $(\bar{w})$ and $\Delta$ density $/ \Delta$ survival for $p_{a}$. Programs in BASIC for the diallel analysis and for the hyperbolic yield-density regression analysis can also be obtained from the authors.

\section{Results}

The primary and corrected $c$-value diallels are given in Table 1, which also contains estimates of the mean pressure (columns) and mean sensitivity (rows) for each diallel and a summary of an analysis of variance for each diallel. Associated with each $c$-value is a unique error based on the replicate error variance pertaining to each indicator genotype. These were pooled to give the estimates shown at the bottom of Table $1 \mathrm{~b}$. The lower figure in each cell, pertaining to the corrected $c$ value diallel, was obtained by dividing each $c$-value by its corresponding monoculture $c$-value, as described by the model,

$c_{x y}^{\prime}=c_{x y} / c_{x x}$

and the error variance associated with this ratio was approximated as follows, using statistical differentials (Davies, 1957)

$$
\begin{aligned}
& \text { if } b=f\left(a_{1}, \ldots, a_{n}\right) \\
& \text { then } \operatorname{var}(b)=\sum_{i=1}^{n}\left(\delta b / \delta a_{i}\right)^{2} \operatorname{var}\left(a_{i}\right)+2 \sum_{i=1}^{n} \sum_{j=i+1}^{n}\left(\delta b / \delta a_{i}\right) \\
& \\
& \quad \times\left(\delta b / \delta a_{j}\right) \operatorname{cov}\left(a_{i}, a_{j}\right)
\end{aligned}
$$

The covariance term was obtained from the covariance regression matrix (Mather \& Caligari, 1981; Snedecor $\&$ Cochran, 1980). The error variances of items in the leading diagonal become zero and are therefore excluded from the pooled error term. Inspection of the primary $c$-values reveals that a gain for one duoculture $c$-value in any $2 \times 2$ comparison generally coincides with a loss for the other duoculture $c$-value, but that these changes are rarely equal. The corrected diallel clarifies this situation considerably, and there is far better parity of duoculture gain and loss in each $2 \times 2$ comparison. These trends can be investigated through the behaviour of the mean sensitivity and mean pressure. The correlation coefficients between sensi- 
Table 1a. Estimates of the primary (upper figure) and corrected (lower figure) $c$-values obtained among the seven genotypes for larval survival $\left(p_{a}\right)$ and mean adult weight $(\bar{w})$. Also given are estimates of the mean pressure and mean sensitivity of each genotype and the results of the analyses of variance of the diallels, including the degrees of freedom for each item (in parentheses), the pooled error variance and the correlation between sensitivity and pressure. Levels of significance are given as $*(0.05>P>0.01) ; * *(0.01>P>0.001) ; * *(0.001>P)$

\begin{tabular}{|c|c|c|c|c|c|c|c|c|}
\hline & \multicolumn{7}{|c|}{ Associate genotype } & \multirow{2}{*}{$\begin{array}{l}\text { Mean } \\
\text { sensitivity }\end{array}$} \\
\hline & + & $y^{2}$ & $\mathrm{pn}$ & w & $\mathrm{w}^{\mathrm{a}}$ & $\mathrm{v}$ & $\mathrm{e}$ & \\
\hline \multicolumn{9}{|c|}{ Indicator genotype } \\
\hline \multirow{4}{*}{$+\frac{p_{a}}{w}$} & 0.4799 & 0.3405 & 0.5012 & 0.1070 & 0.5671 & 0.5647 & 0.2701 & 0.4044 \\
\hline & 1 & 0.7094 & 1.0443 & 0.2229 & 1.1816 & 1.1767 & 0.5628 & 0.8425 \\
\hline & 0.01831 & 0.01740 & 0.02136 & 0.01294 & 0.02229 & 0.02108 & 0.01720 & 0.01865 \\
\hline & 1 & 0.9503 & 1.1666 & 0.7067 & 1.2174 & 1.1513 & 0.9394 & 1.0188 \\
\hline \multirow{4}{*}{$\mathrm{y}^{2} \frac{p_{a}}{w}$} & 0.2511 & 0.1794 & 0.2399 & 0.0676 & 0.3092 & 0.4107 & 0.1291 & 0.2267 \\
\hline & 1.3992 & 1 & 1.3371 & 0.3765 & 1.7234 & 2.2885 & 0.7192 & 1.2634 \\
\hline & 0.02054 & 0.02273 & 0.02063 & 0.00744 & 0.02589 & 0.02905 & 0.01628 & 0.02037 \\
\hline & 0.9034 & 1 & 0.9077 & 0.3273 & 1.1392 & 1.2779 & 0.7163 & 0.8960 \\
\hline \multirow{4}{*}{ pn $\frac{p_{a}}{w}$} & 0.3766 & 0.2458 & 0.3025 & 0.1380 & 0.2819 & 0.5447 & 0.2530 & 0.3061 \\
\hline & 1.2448 & 0.8123 & 1 & 0.4563 & 0.9319 & 1.8006 & 0.8362 & 1.0117 \\
\hline & 0.02469 & 0.02264 & 0.02452 & 0.00938 & 0.02614 & 0.03159 & 0.01584 & 0.02211 \\
\hline & 1.0069 & 0.9233 & 1 & 0.3825 & 1.0661 & 1.2883 & 0.6460 & 0.9019 \\
\hline \multirow{4}{*}{$\mathrm{w} \frac{p_{a}}{w}$} & 0.7149 & 0.6074 & 0.6512 & 0.3710 & 0.6544 & 0.7684 & 0.4692 & 0.6052 \\
\hline & 1.9271 & 1.6373 & 1.7554 & 1 & 1.7639 & 2.0711 & 1.2648 & 1.6314 \\
\hline & 0.02983 & 0.03722 & 0.03428 & 0.02048 & 0.03335 & 0.02254 & 0.02524 & 0.02899 \\
\hline & 1.4565 & 1.8174 & 1.6738 & 1 & 1.6284 & 1.1006 & 1.2324 & 1.4155 \\
\hline \multirow{4}{*}{$\mathrm{w}^{\mathrm{a}} \frac{p_{a}}{w}$} & 0.1549 & 0.0838 & 0.0764 & 0.0386 & 0.0948 & 0.1856 & 0.0421 & 0.0966 \\
\hline & 1.6336 & 0.8841 & 0.8058 & 0.4067 & 1 & 1.9567 & 0.4443 & 1.0187 \\
\hline & 0.01777 & 0.02253 & 0.01987 & 0.00862 & 0.02508 & 0.02619 & 0.01141 & 0.01878 \\
\hline & 0.7085 & 0.8983 & 0.7923 & 0.3437 & 1 & 1.0443 & 0.4549 & 0.7488 \\
\hline \multirow{4}{*}{$\mathrm{v} \frac{p_{a}}{\bar{w}}$} & 0.5690 & 0.3955 & 0.4393 & 0.2108 & 0.4635 & 0.6086 & 0.3063 & 0.4276 \\
\hline & 0.9350 & 0.6499 & 0.7219 & 0.3464 & 0.7617 & 1 & 0.5033 & 0.7026 \\
\hline & 0.02158 & 0.02219 & 0.02269 & 0.00811 & 0.02079 & 0.03021 & 0.01461 & 0.02003 \\
\hline & 0.7143 & 0.7345 & 0.7511 & 0.2685 & 0.6882 & 1 & 0.4836 & 0.6629 \\
\hline \multirow{4}{*}{$\mathrm{e} \frac{p_{a}}{w}$} & 0.6718 & 0.6869 & 0.6733 & 0.2940 & 0.7941 & 0.9375 & 0.4962 & 0.6505 \\
\hline & 1.3540 & 1.3844 & 1.3570 & 0.5926 & 1.6004 & 1.8896 & 1 & 1.3111 \\
\hline & 0.01940 & 0.02063 & 0.01923 & 0.01490 & 0.02769 & 0.02722 & 0.01823 & 0.02104 \\
\hline & 1.0642 & 1.1317 & 1.0549 & 0.8174 & 1.5190 & 1.4932 & 1 & 1.1542 \\
\hline \multicolumn{9}{|c|}{ Mean pressure } \\
\hline \multirow{4}{*}{$\frac{p_{a}}{\bar{w}}$} & 0.4597 & 0.3628 & 0.4120 & 0.1753 & 0.4521 & 0.5743 & 0.2809 & \\
\hline & 1.3562 & 1.0111 & 1.1459 & 0.4859 & 1.2804 & 1.7405 & 0.7615 & \\
\hline & 0.02173 & 0.02362 & 0.02323 & 0.01170 & 0.02589 & 0.02684 & 0.01697 & \\
\hline & 0.9791 & 1.0651 & 1.0495 & 0.5494 & 1.1798 & 1.1937 & 0.7818 & \\
\hline
\end{tabular}

Table 1b.

\begin{tabular}{llclll}
\hline MS & Sensitivity $_{(6)}$ & Pressure $_{(6)}$ & $\mathrm{S} \times \mathrm{P}_{(36)}$ & Pooled error $_{(426)}$ & $r_{(5)}$ \\
\hline$p_{a}$ & $\left\{\begin{array}{l}0.2748^{* * *} \\
0.6896^{* * *}\end{array}\right.$ & $0.1189^{* * *}$ & 0.0041 & $2.96 \times 10^{-3}$ & -0.532 \\
$8.820 \times 10^{-5 * * *}$ & $1.1773^{* * *}$ & 0.0400 & 0.05416 & $-0.974^{* * *}$ \\
$0.4523^{* * *}$ & $0.099 \times 10^{-5 * * *}$ & $1.172 \times 10^{-5}$ & $0.6526 \times 10^{-5}$ & $-0.821^{* *}$ \\
& & $0.3756^{* * *}$ & 0.0225 & 0.01952 & $-0.987^{* * *}$ \\
\hline
\end{tabular}


tivity and pressure for the primary $c$-values are shaped by the relative amounts of variation for the utilization efficiency and the feeding rate, as explained in the previous section. The non-significant correlation for $p_{a}$ therefore implies that for survival the utilization efficiency is a more important factor in competition than for mean adult weight $(\bar{w})$, where this correlation is much larger, and highly significant. In the corrected diallel these correlations are considerably enhanced as was predicted by the competition diallel model. This has also been noticed by McGilchrist \& Trenbath (1971). Another observation is that for many $2 \times 2$ comparisons in the corrected diallel the duoculture average exceeds 1.0 , which implies the presence of negative interference. The analyses of variance for the corrected diallels reveal that there is more variation for pressure than for sensitivity in the case of $p_{a}$, while for $\bar{w}$ the reverse is true. Consequently the data for $p_{a}$ were analysed with the competition diallel model that included general interference $(i)$ as a column effect, while the data for $\bar{w}$ were analysed with $i$ as a row effect. The results of the analysis are summarized in Table 2. Also shown are the approximate percentage contributions by the utilization efficiencies $(u)$, the relative feeding rates $(f)$, the general interference $(i)$ and the residual variation representing specific interference $(j)$ to the total variation in the primary $c$-value diallel. These data show that the three main parameters $(u, f$ and $i$ ) account for nearly all the variation in competitive ability, affirming both the accuracy of the model and suggesting that there is very little specific interference in Drosophila competition. The utilization efficiency $(u)$ is the single most important contributor to $c$-value variation in $p_{a}$ while the feeding rate differences $(f)$ are the most important components for weight-based competition $(\bar{w})$. This concurs with the

Table 2a. Estimates and error variances ( 426 degrees of freedom each) for the utilization efficiency $(u)$, relative feeding rate $(f)$ and general interference $(i)$ of the seven genotypes for larval survival $\left(p_{a}\right)$ and mean adult weight $(\bar{w})$. Also shown is the total $c$-value variation, and the variation in the corrected diallel after adjusting for $u$, for $u$ and $f$, and for $u, f$ and $i$. These were used to estimate the approximate percentage contributions of $u, f, i$ and $j$ to the total $c$-value variation in both $p_{a}$ and $\bar{w}$. Levels of significance are as given in Table 1

\begin{tabular}{|c|c|c|c|c|c|c|}
\hline & \multicolumn{3}{|l|}{$p_{a}$} & \multicolumn{3}{|l|}{$\bar{w}$} \\
\hline & $u$ & $f$ & $i$ & $u$ & $f$ & $i$ \\
\hline+ & 2.0838 & 1.2740 & -0.0959 & 54.6212 & 1.0191 & -0.0444 \\
\hline var & 0.07038 & 0.005599 & 0.01986 & 20.69431 & 0.00232 & 0.00716 \\
\hline$y^{2}$ & 5.5741 & 0.8380 & -0.2019 & 43.9903 & 1.0976 & 0.0076 \\
\hline var & 0.92582 & 0.006173 & 0.01986 & 3.28534 & 0.00166 & 0.00716 \\
\hline $\mathrm{pn}$ & 3.3058 & 1.1131 & -0.0383 & 40.7844 & 1.0802 & 0.0209 \\
\hline var & 0.35959 & 0.005396 & 0.01986 & 3.33817 & 0.00167 & 0.00716 \\
\hline w & 2.6954 & 0.5015 & 0.0181 & 48.8303 & 0.5827 & 0.0019 \\
\hline var & 0.11248 & 0.005042 & 0.01986 & 14.64603 & 0.00313 & 0.00716 \\
\hline $\mathrm{w}^{\mathrm{a}}$ & 10.5485 & 1.0777 & -0.2365 & 39.8688 & 1.2059 & 0.0528 \\
\hline var & 8.77827 & 0.009380 & 0.01986 & 1.91899 & 0.00205 & 0.00716 \\
\hline $\mathrm{v}$ & 1.6431 & 1.3651 & -0.4379 & 33.1053 & 1.2053 & 0.1537 \\
\hline var & 0.02181 & 0.006810 & 0.01986 & 2.42604 & 0.00217 & 0.00716 \\
\hline $\mathrm{e}$ & 2.0153 & 0.8306 & 0.0807 & 54.8583 & 0.8093 & 0.0424 \\
\hline var & 0.08883 & 0.004848 & 0.01986 & 22.81543 & 0.00257 & 0.00716 \\
\hline
\end{tabular}

Table 2b.

\begin{tabular}{llrlrl}
\hline & $p_{a}$ & & & & $\bar{w}$ \\
\hline $1 / u_{x}\left[1-\left(f_{x}-f_{y}\right)-i_{x}\right]$ & $\chi_{(48)}^{2}=826.01^{* * *}$ & $72.0 \%$ & $u$ & $10.6 \%$ & $\chi_{(48)}^{2}=328.53^{* * *}$ \\
$1-\left(f_{x}-f_{y}\right)-i_{x}$ & $\chi_{(41)}^{2}=231.54^{* * *}$ & $21.2 \%$ & $f$ & $74.9 \%$ & $\chi_{(41)}^{2}=293.61^{* * *}$ \\
$1-i_{x}$ & $\chi_{(34)}^{2}=56.10^{* *}$ & $4.1 \%$ & $i$ & $2.9 \%$ & $\chi_{(34)}^{2}=47.62 \mathrm{~ns}$ \\
Residual & $\chi_{(27)}^{2}=22.21 \mathrm{~ns}$ & $2.7 \%$ & $j$ & $11.6 \%$ & $\chi_{(27)}^{2}=38.19 \mathrm{~ns}$ \\
\hline
\end{tabular}


interpretation of the correlation coefficients between sensitivity and pressure, and can be ascribed to the different nature of larval survival and adult weight determination. The number of larvae that survive depends on the larval food conversion efficiency and on reaching a minimum larval pupation weight early in the third instar stage. This is an important utilizationrelated parameter and for which there is considerable genetic varitation (Bakker, 1961). The mean adult weight is directly related to the final larval weight which is reached well after survival has been assured, and is therefore less affected by the critical weight. As a result the $c$-values for $p_{a}$ are probably more influenced by efficiency parameters than those for $\bar{w}$. It is also evident that interference in Drosophila larval competition is mostly negative when concerning larva-adult survival $\left(p_{a}\right)$ and positive when concerning mean adult weight $(\bar{w})$. None of the six parameters are related to any significant degree with the obvious exception of the relative feeding rates in $p_{a}$ and $\bar{w}\left(r_{5}=0.811 ; P<0.05\right)$. The utilization efficiencies for $p_{a}$ and $\bar{w}$ are unrelated, as is the case for general interference. There is a moderate correlation between high feeding rate and low efficiency in $\bar{w}\left(r_{5}=-0.655\right)$, which is only of interest because direct physiological studies of the larval feeding behaviour showed similar low level, nonsignificant but consistent correlations between the larval feeding rates and the larva adult food conversion efficiencies, for both second and third instar larvae (de Miranda, 1987).

\section{Discussion}

There are two main points for discussion, namely the diallel model and the interpretation of larval interference and food exploitation in Drosophila. In these experiments the model gave an excellent description of the data, corroborated by independent analyses of the data on several occasions. The exploitation component of competition (represented by the utilization efficiency and the feeding rates) accounted for the bulk of the variation in the primary $c$-value diallels, both when using survival $\left(p_{a}\right)$ and mean adult weight $(\bar{w})$ as a marker for competitive success. Unfortunately, it is not possible to judge the model by its ability to explain the variation in the diallels because an analysis of variance also provides an adequate fit to the data. This may be due to the closely controlled environmental conditions of these experiments which leave little opportunity for niche partitioning and interference which in turn are the major contributors to the interaction between sensitivity and pressure. Such interaction is more likely to be found in plant competition (Breese \& Hill, 1973; Mather et al., 1982) and it would be interesting to know how the model behaves in these situations. The model also explains conflicting evidence from previous studies. For example, it had been found that estimates of sensitivity and pressure were generally not correlated implying independence (Mather \& Caligari, 1983; Eggleston, 1985; de Miranda \& Eggleston, 1987). However, when age differences between indicator and associate genotypes were introduced (de Miranda, 1987) or when either sensitivity or pressure were selected for (Hemmat \& Eggleston, 1988a), the sensitivity and pressure were found to be closely related. Such relatedness is of course due to the feeding rate differences, while the apparent unrelatedness is caused by the variation in utilization efficiency. In the study of larval age differences it is largely the differences in feeding rate that are affected; the utilization efficiency (food conversion efficiency and critical weight) is less affected by the age differences. Consequently the changes in sensitivity and pressure due to increasing age differences are very closely linked. This is less the case with the selection study because selection could affect both the feeding rate and the utilization efficiency. However, the larval feeding rate is very heterotic (Sewell et al., 1975; Burnet et al., 1977) and the selection study involved a high degree of inbreeding which would strongly affect the feeding rate. Hence, sensitivity and pressure would appear to be related to a degree, depending on whether the utilization efficiency was affected by inbreeding or not. The potentially different genetic nature of feeding rate and utilization efficiency has also been implicated in the high levels of heterosis observed for pressure but not for sensitivity (de Miranda \& Eggleston, 1988c, 1989). With respect to larval interference these results are in general agreement with previous studies (Hemmat \& Eggleston, 1988b) who also found mostly negative heterotypic interference when studying larval survival. On a wider basis the model has shown that all major components of competition (density, acquisition rate, utilization efficiency and interference) can be estimated from relatively simple data. All effects can be transposed to any absolute or relative density, and from these the RYT or LER of any mixture can be predicted (Spitters, 1983b). It is imperative, however, that very accurate estimates of the monoculture regression coefficients are obtained because division by the monoculture $c$-values is the focal point of the diallel model and of any subsequent extrapolation. The model may also be useful in selection studies as it can separate those characteristics important to monoculture yield (primarily the utilization efficiency) from mixturerelated phenomena (acquisition rate differences and interference). The model is most useful in data analysis because it lacks the environmental input and the 
temporal element to make it a truly predictive model, certainly in comparison with the physiological growth simulation models. For example, the proportion of the resource that is shared, and therefore subject to acquisition rate differences, changes as competition progresses; seedlings grown at low density initially behave as if grown in isolation, and it is only later that the plants start to compete for each others' resources. Such changes are not accounted for by the model, which simply averages all effects up to the time of harvest. Secondly, the use of very low densities in mixed cropping, where there is likely to be a departure from the simple relationship between density and yield, may cause the interference effects to be overestimated (Spitters, 1983b). More complex formulae for the relationship between density and yield (e.g. Benjamin, 1988) may be able to reduce this bias. Thirdly, the acquisition rate is often related to size, both in plants (Ford \& Diggle, 1981; Cannell et al., 1984; Benjamin, 1988) and Drosophila (Altapov, 1929; Bakker, 1961; Nunney, 1983; de Miranda \& Eggleston, 1988a) and therefore increases exponentially with time. This means that the relative acquisition rates, as estimated by the diallel model, diverge as competition progresses and probably more accurately reflect the final acquisition rate rather than the mean acquisition rate over the whole growing period. It is possible to obtain absolute estimates of the plant acquisition rate from monoculture data only. If we assume the rate of growth of a plant at any one time ( $\Delta$ weight/ $\Delta$ time $)$ to be the product of the acquisition rate $(\Delta$ space $/ \Delta$ time $)$ and the utilization efficiency ( $\Delta$ weight $/ \Delta$ space) and then from the rate of growth of a plant and its density response we can obtain an estimate of the acquisition rate at that time. Any one of a number of characters (biomass, plant height, leaf area) could be used to define the growth rate of a plant, depending on what resource is likely to be limiting. Such estimates could be used to predict the exploitation component of competition in the diallel model. However, the interference component of competition would still have to be obtained from duoculture data or would have to be inferred from the biology of the competitors.

\section{Acknowledgements}

The financial assistance of the SERC (JRdM), the Iranian Ministry of Education $(\mathrm{MH})$ and the Lister Institute of Preventative Medicine (PE) is gratefully acknowledged.

\section{References}

ALTAPOV, w. w. 1929. Growth and variation of the larvae of Drosophila melanogaster. J. Exp. Zool., 52, 407-432.
BAAN-HOFMAN, T. AND ENNIK, G. C. 1982. The effect of rootmass of perennial ryegrass (Lolium perenne L.) on the competitive ability with respect to couchgrass (Elytrigia repens (L.) Desv.). Neth. J. Agric. Sci., 30, 275-283.

BAKKER, K. 1961. An analysis of factors which determine success in competition for food among larvae of Drosophila melanogaster. Neth. J. Zool., 19, 541-595.

BENJAMIN, L. R. 1988. A single equation to quantify the hierarchy in plant size induced by competition within monocultures. Ann. Bot., 62, 199-214.

VAN DEN BERGH, J. P. 1968. An analysis of yields of grasses in mixed and pure stands. Versl. Landb. Onderz., 714, 1-71.

BIRCH, L. C. 1957. The meanings of competition. Am. Nat., 91, 5-18.

BREESE, E. L. AND HILL, J. 1973. Regression analysis of interactions between competing species. Heredity, 31, 181-200.

BUDNIK, M. AND BRNCIC, D. 1975. Effects of larval biotic residues on viability in four species of Drosophila. Evolution, 29, 777-780.

BURNET, B., SEWELL, D. AND BOS, M. 1977. Genetic analysis of larval feeding behaviour in Drosophila melanogaster. II. Growth relations and competition between selected lines. Gen. Res. Camb., 30, 149-161.

CANNEll, M. G. R., ROTHERY, P. AND FORD, E. D. 1984. Competition within stands of Picca sitchensis and Pinus contorta. Ann. Bot., 53, 349-362.

CHOWDURY, A. R. AND HODGSON, D. R. 1982. Growth and yield in pure and mixed crops of potato cultivars. J. Agric. Sci. Camb., 98, 505-516.

DAVIES, o. L. 1957. Statistical Methods in Research and Production. Oliver and Boyd, Edinburgh.

DAWOOD, M. AND STRICKBERGER, M. 1964. The effect of larval interaction on viability in Drosophila melanogaster. Genetics, 50, 999-1007.

EGGLESTON, P. 1985. Variation for aggression and response in the competitive interactions of Drosophila melanogaster. Heredity, 54, 43-51.

FORD, E. D. AND DIGGLE, P. J. 1981. Competition for light modelled as a spatially stochastic process. Ann. Bot., 48, 481-500.

GODOY-HERRERA, R. 1977. Intra- and interpopulational variation in digging in Drosophila melanogaster larvae. Behavl Gen., 8, 475-479.

HARPER, J. L. 1967. A Darwinian approach to plant ecology. J. Ecol., 55, 247-270.

HEMMAT, M. AND EGgleston, P. 1988a. Competitive interactions in Drosophila melanogaster. recurrent selection for aggression and response. Heredity, 60, 129-137.

HEMMAT, M. AND EGgleston, P. 1988b. Competitive interactions in Drosophila melanogaster: genetic variation for interference media conditioning. Heredity, 61, 347-354.

HILL, J. 1990. The three C's - competition, coexistence and coevolution - and their impact on the breeding of forage crop mixtures. Theor. Appl. Gen., 79, 168-176.

JOHNSON, I. R., PARSONS, A. J. AND LUDLOW,, M. M. (1989). Modelling photosynthesis in monocultures and duocultures. Aus. J. Pl. Phys., 16, 501-516.

LIM, J. T., WILKERSON, G. G., RAPER, C. D. AND GOLD, H. J. (1990). Dynamic growth model of vegetative soya bean plants: model structure and behaviour under varying root tem- 
perature and nitrogen concentration. J. Exp. Bot., 41, 229-241.

LINDSLEY, D. L. AND GRELL, E. H. 1967. Genetic variations of Drosophila melanogaster. Carnegie Inst. of Washington publ., 627, Washington.

LINNEY, R., BARNES, B. W. AND KEARSEY, M. J. 1971. Variation for metrical charcters in Drosophila populations. Heredity, 27, 163-174.

MCGILCHRIST, C. A. 1965. Analysis of competition experiments. Biometrics, 21, 975-985.

MCGILCHRIST, C. A. AND TRENBATH, B. R. 1971. A revised analysis of plant competition experiments. Biometrics, 27, 659-671.

MATHER, K. AND CALIGARI, P. D. S. 1981. Competitive interactions in Drosophila melanogaster. II. Measurement of competition. Heredity, 46, 239-254.

MATHER, K. AND CALIGARI, P. D. S. 1983. Pressure and response in competitive interactions. Heredity, 51, 435-454.

MATHER, K., HILL, J. AND CALIGARI, P. D. S. 1982. Analysis of competitive ability among genotypes of perennial ryegrass. Heredity, 48, 421-434.

DE MIRANDA, J. R. 1987. Competitive interactions in Drosophila melanogaster. PhD thesis, University of Liverpool.

DE MIRANDA, J. R. AND EGGLESTON, P. 1987. A comparison of substitution and addition designs for the analysis of competitive interactions in Drosophila melanogaster. Heredity, $\mathbf{5 8}, 279-288$.

DE MIRANDA, J. R. AND EGGLESTON, P. 1988a. Larval competition in Drosophila melanogaster. I. Estimation of larval growth parameters. Heredity, 60, 205-212.

DE MIRANDA, J. R. AND EGGLESTON, P. 1988b. Larval competition in Drosophila melanogaster. II. Comparing biological and competitive parameters. Heredity, 60, 213-219.

DE MIRANDA, J. R. AND EGGLESTON, P. 1988c. Genetic analysis of larval competition in Drosophila melanogaster. Heredity, 61, 339-346.

DE MiRANDA, J. R. AND EGGLESTON, P. 1989. Analysis of dominance for competitive ability in Drosophila melanogaster. Heredity, 63, 221-229.

NORRINGTON-DAVIES, J. 1967. Application of diallel analysis to experiments in plant competition. Euphytica, 16, 391-406.

NORRINGTON-DAVIES, J. 1968. Diallel analysis of competition between grass species. J. Agric. Sci. Camb., 71, 223-231.

NUNNEY, L. 1983. Sex differences in larval competition in Drosophila melanogaster: the testing of a competition model and its relevance to frequency dependent selection. Am. Nat., 121, 67-93.

SANG, J. H. 1949. The ecological determinants of population growth in a Drosophila culture. III. Larval and pupal survival. Physiol. Zool., 22, 183-202.

SEWELL, D., BURNET, B. AND CONNOLLY, K. 1975. Genetic analysis of larval feeding behaviour in Drosophila melanogaster. Gen. Res. Camb., 24, 163-173.

SNEDECOR, G. W. AND COChran, w. G. 1980. Statistical Methods, 7 th edn, Iowa State University Press, Iowa, USA.

sokolowski, м. в. 1982. Drosophila larval foraging strategy: digging. Anim. Behav., 30, 1252-1253.

SPITTERS, C. J. T. 1979. Competition and its consequences for selection in plant breeding. Versl. Landb. Onderz., 893, 1-268.

SPITTERS, C. J. T. 1983a. An alternative approach to the analysis of mixed cropping experiments. 1. Estimation of competition effects. Neth. J. Agric. Sci., 31, 1-11.

SPITTERS, C. J. T. $1983 \mathrm{~b}$. An alternative approach to the analysis of mixed cropping experiments. 2. Marketable yield. Neth. J. Agric. Sci., 31, 143-155.

SPITTERS, C. J. T. 1986. A confrontation between a descriptive and an explanatory approach to inter-genotypic competition. Proceedings of the 6th Meeting EUCARPIA Section Biometrics in Plant Breeding, pp. 205-229. Birmingham, UK.

SPITTERS, C. J. T. AND AERTS, R. 1983. Simulation of competition for light and water in crop-weed associations. Aspects Appl. Biol., 4, 467-483.

SPITTERS, C. J. T., KROPFF, M. J. AND DE GROOT, w. 1989. Competition between maize and Echinochloa crus-galli analysed by a hyperbolic regression model. Ann. Appl. Biol., 115, 541-551.

WEISBROT, D. R. 1966. Genotypic interactions among competing strains of Drosophila. Genetics, 53, 427-435.

WILLEY, R. W. AND OSIRU, D. S. O. 1972. Studies on mixtures of maize and beans (Phaseolus vulgaris) with particular reference to plant population. J. Agric. Sci. Camb., 79, 519-529.

WILliams, E. J. 1962. The analysis of competition experiments. Aus. J. Biol. Sci., 15, 509-525.

DE WIT, C. T. AND VAN DEN BERGH, J. P. 1965. Competition between herbage plants. Neth. J. Agric. Sci., 13, 212-221.

WRIGHT, A. J. 1981. The analysis of yield-density relationships in binary mixtures using inverse polynomials. J. Agric. Sci. Camb., 96, 561-567. 